\title{
Haemodynamic studies at rest and during exercise in pulmonary stenosis after surgery
}

\author{
P. Finnegan, H. N. C. Ihenacho, S. P. Singh, and L. D. Abrams \\ From the Department of Medicine, Queen Elizabeth Hospital, Brimingham and Birmingham Children's Hospital
}

Fourteen patients with pulmonary stenosis had circulatory studies performed I to I4 years after operation. Preoperatively, the mean right ventricular systolic pressure was $105 \mathrm{mmHg}(S D=25)$. After operation the mean right ventricular systolic pressure for the group was $31 \mathrm{mmHg}(S D=7)$, and during exercise it increased to $46 \mathrm{mmHg}(S D=6)$. The mean pulmonary systolic gradient before operation was $88 \mathrm{mmHg}(S D=2 I)$ and after operation it was II $\mathrm{mmHg}(S D=2)$. The mean cardiac index at rest was $4.01 . /$ min per $m^{2}(S D=0.9)$ and it increased to $7 \cdot I \mathrm{l} . / \mathrm{min}$ per $\mathrm{m}^{2}(S D=I \cdot 0)$ on exercise. The relation between oxygen consumption and cardiac output during exercise was normal in all patients.

The results of this study indicate that a normal cardiac output response to exercise may be regularly achieved after successful surgical treatment of pulmonary stenosis.

Although it is widely believed that pulmonary valvotomy is a successful operation, the only two postoperative haemodynamic studies have shown persistent abnormalities in a high proportion of patients. It was found by Johnson (I962) that 7 of the 17 patients studied had an abnormal cardiac output response during exercise. The other postoperative study (Jonsson and Lee, 1968) showed that 4 of the 9 patients investigated had an impaired cardiac output response during exercise. Several possible mechanisms have been proposed to explain the abnormal postoperative haemodynamics. It has been suggested that the tendency for a low cardiac output during exercise after operation was due to an adaptation of the peripheral circulation which allowed greater extraction and utilization of oxygen (Jonsson and Lee, 1968). A more likely explanation is that increased resistance to right ventricular filling caused by myocardial fibrosis was the most important factor (Johnson, 1962). The presence of patchy myocardial fibrosis has been shown in patients with pulmonary stenosis (Allanby and Campbell, 1949).

Investigation of patients with pulmonary stenosis before operation (Dow et al., 1950; Lewis et al., 1964; Howitt, 1966; Ikkos, Jonsson and Linderholm, 1966; Moller, Rao, and Lucas, 1972) has shown that, in general, patients with mild and moderate stenosis had normal exercise haemo-

Received 26 November 1973. dynamics. However, many patients with severe pulmonary stenosis had an impaired cardiac output response during exercise. Some of the patients investigated postoperatively by Johnson had moderate to severe residual pulmonary stenosis (Johnson, 1962) and 3 of the patients studied by Jonsson and Lee (1968) had moderate residual stenosis. It is possible, therefore, that adequate surgical relief of the pulmonary stenosis with consequent reduction in ventricular hypertrophy and increased ventricular compliance could result in normal exercise haemodynamics. The present study examines the postoperative haemodynamics in 14 patients who had moderate to severe pulmonary stenosis preoperatively. Every patient was shown to have a normal cardiac output response during exercise.

\section{Patients and methods}

Fourteen patients, 6 male and 8 female, were investigated I to 14 years (mean 7 years) after operation for pulmonary stenosis with intact ventricular septum. All the patients were asymptomatic at the time of investigation and were selected only on the basis of their willingness to participate in the study.

Preoperative clinical and haemodynamic data are shown in Table I. Open pulmonary valvotomy was performed in 12 patients on cardiopulmonary bypass. Infundibular resection alone for anatomical infundibular stenosis was done on Cases 3 and 6. Cases 5 and ro had resection of anatomical infundibular stenosis as well as pulmonary valvotomy. Cases 2 and ro had small ostium secundum atrial septal defects which were closed. 
TABLE I Preoperative clinical and haemodynamic data

\begin{tabular}{|c|c|c|c|c|c|}
\hline $\begin{array}{l}\text { Case } \\
\text { No. }\end{array}$ & Sex & $\begin{array}{l}\text { Age at } \\
\text { operation } \\
(y r)\end{array}$ & $\begin{array}{l}\text { Right } \\
\text { ventricular } \\
\text { pressure } \\
(\text { mmHg })\end{array}$ & $\begin{array}{l}\text { Pulmonary } \\
\text { arterial } \\
\text { pressure } \\
(\mathrm{mmHg})\end{array}$ & $\begin{array}{l}\text { Pulmonary- } \\
\text { right ventricular } \\
\text { systolic gradient } \\
(\mathrm{mmHg})\end{array}$ \\
\hline I & F & 14 & $160 / 10$ & $35 /-$ & 125 \\
\hline 2 & $\mathbf{M}$ & 6 & $80 / 2$ & $22 /-$ & 58 \\
\hline 3 & $\mathbf{F}$ & 5 & $105 / 5$ & $10 / 7$ & 95 \\
\hline 4 & $\mathbf{F}$ & 14 & $115 / 10$ & $28 / 12$ & 87 \\
\hline 5 & $\mathbf{M}$ & 8 & $105 / 5$ & $15 /-$ & 90 \\
\hline 6 & $\mathrm{~F}$ & 6 & $90 / 10$ & - & - \\
\hline 7 & $\mathbf{M}$ & 6 & $100 / 10$ & 10/- & 90 \\
\hline 8 & $\mathrm{~F}$ & 13 & - & - & - \\
\hline 9 & F & 9 & $85 / 8$ & $24 / 7$ & $6 I$ \\
\hline 10 & $\mathbf{M}$ & 9 & $130 / 0$ & $25 / 5$ & 105 \\
\hline II & $\mathbf{M}$ & 9 & $108 / 0$ & $18 / 5$ & 90 \\
\hline 12 & $\mathbf{M}$ & 6 & - & - & - \\
\hline 13 & $\mathbf{M}$ & 49 & $66 / 5$ & $10 / 5$ & 56 \\
\hline 14 & $\mathrm{~F}$ & 15 & $120 / 5$ & $16 / 8$ & 104 \\
\hline
\end{tabular}

Preoperatively the right ventricular systolic pressure exceeded $80 \mathrm{mmHg}$ in II patients. According to the criteria of Wood (I956), 8 patients had severe pulmonary stenosis (right ventricular systolic pressure $>100 \mathrm{mmHg}$ ) and 4 were moderate (right ventricular systolic pressure $>50 \mathrm{mmHg}$ ); Case 12 was not catheterized before operation but his electrocardiogram showed grade 4 right ventricular hypertrophy. Preoperative data on Case 8 were unobtainable.

Before operation the electrocardiograms of 6 patients showed grade 4 right ventricular hypertrophy (Goodwin and Abdin, 1959), I had grade 3, 5 had grade 2, and I showed no evidence of right ventricular hypertrophy. At the time of postoperative study 6 patients had normal electrocardiograms, I patient had grade 4, and I patient grade 2 right ventricular hypertrophy. Six patients showed a right bundle-branch block pattern.

\section{Circulatory studies after operation}

Right heart catheterization was performed in the fasting state and the patients were not sedated. A No. 9 double lumen Cournand catheter was passed into the pulmonary artery and the resting pulmonary valve pressure gradient was recorded while withdrawing the catheter to the right ventricle. The pressure gradient during exercise was measured by withdrawing the proximal lumen of the catheter to the right ventricle. The pressures were measured by (Sanborn model $267 \mathrm{BC}$ ) transducers and recorded on an ultraviolet photographic recorder. The

TABLE 2 Postoperative haemodynamic data

\begin{tabular}{|c|c|c|c|c|c|c|c|c|c|}
\hline \multirow[t]{2}{*}{$\begin{array}{l}\text { Case } \\
\text { No. }\end{array}$} & & \multicolumn{2}{|c|}{$\begin{array}{l}\text { Right ventricular } \\
\text { systolic pressure } \\
(\mathrm{mmHg})\end{array}$} & \multicolumn{2}{|c|}{$\begin{array}{l}\text { Right ventricular } \\
\text { end-diastolic } \\
\text { pressure } \\
(\mathrm{mmHg})\end{array}$} & \multicolumn{2}{|c|}{$\begin{array}{l}\text { Mean pulmonary } \\
\text { arterial pressure } \\
(\mathrm{mmHg})\end{array}$} & \multicolumn{2}{|c|}{$\begin{array}{l}\text { Pulmonary- } \\
\text { right ventricular } \\
\text { systolic gradient } \\
(\mathrm{mmHg})\end{array}$} \\
\hline & & Rest & Exercise & Rest & Exercise & Rest & Exercise & Rest & Exercise \\
\hline I & & 38 & 55 & 8 & 5 & 14 & 19 & I9 & 32 \\
\hline 2 & & 28 & 44 & 2 & 7 & 13 & 20 & IO & 25 \\
\hline 3 & & 25 & 38 & 4 & 3 & II & 22 & 6 & 8 \\
\hline 4 & & 37 & 44 & 4 & 6 & 15 & I8 & 13 & I4 \\
\hline 5 & & 33 & 53 & 4 & I & 12 & 13 & 14 & 35 \\
\hline 6 & & 40 & - & IO & - & 15 & 20 & 16 & - \\
\hline 7 & & 34 & 42 & 5 & I0 & 13 & 17 & I5 & I9 \\
\hline 8 & & 22 & 32 & 3 & 4 & 8 & 10 & 9 & 16 \\
\hline 9 & & 39 & $5 I$ & 5 & 4 & 17 & 22 & 13 & 20 \\
\hline I0 & & 34 & 54 & I0 & I3 & 16 & 20 & 6 & II \\
\hline I I & & 30 & 47 & 7 & 3 & 13 & 20 & 12 & 20 \\
\hline 12 & & 19 & 44 & 7 & 8 & I I & I6 & 5 & 23 \\
\hline I3 & & $2 I$ & 50 & 2 & 6 & 8 & 20 & I0 & 22 \\
\hline \multirow[t]{3}{*}{14} & & 28 & 49 & $\mathbf{I}$ & 6 & I I & 20 & 9 & $2 I$ \\
\hline & Mean $=$ & $3 I$ & 46 & $4 \cdot 6$ & $5 \cdot 4$ & 13 & 18 & II & 20 \\
\hline & $\mathrm{SD}=$ & 7 & 6 & 3 & 3 & 3 & 3 & 2 & 8 \\
\hline
\end{tabular}


pulmonary artery and right ventricular pressures were determined over several respiratory cycles. The right ventricular end-diastolic pressure was measured after the ' $a$ ' wave. The reference point for zero pressure was $5 \mathrm{~cm}$ below the sternal angle. Cardiac output was measured by the direct Fick method. The oxygen saturation of blood samples from the pulmonary and brachial arteries was determined by a spectrophotometric method. The expired air was collected simultaneously in a Tissot spirometer, and gas samples were analysed for oxygen content by the Scholander micro-method. Measurements were made at rest and during the fifth minute of supine submaximal exercise with a bicycle ergometer.

\section{Results}

Right heart pressures (Table 2)

The mean right ventricular systolic pressure at rest was $31 \mathrm{mmHg}(\mathrm{SD}=7)$; it increased on exercise to $46 \mathrm{mmHg}(\mathrm{SD}=6)$. The mean systolic pressure gradient across the pulmonary valve at rest was II $\mathrm{mmHg}(\mathrm{SD}=2)$ and this increased on exercise to $20 \mathrm{mmHg}(\mathrm{SD}=8)$. The individual responses are shown in Fig. $I$.

The mean right ventricular end-diastolic pressure at rest was $4.6 \mathrm{mmHg}(\mathrm{SD}=3)$; it increased on exercise in 8 patients, and decreased in 5 (Fig. 2). The mean pressure on exercise was $5.4 \mathrm{mmHg}(\mathrm{SD}=3)$.

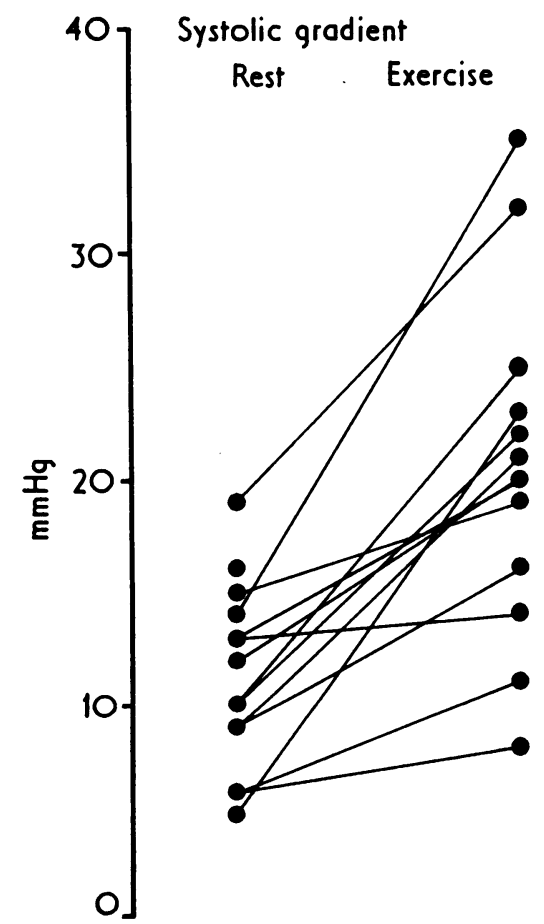

FIG. I The pulmonary artery-right ventricular systolic gradient at rest and during exercise.

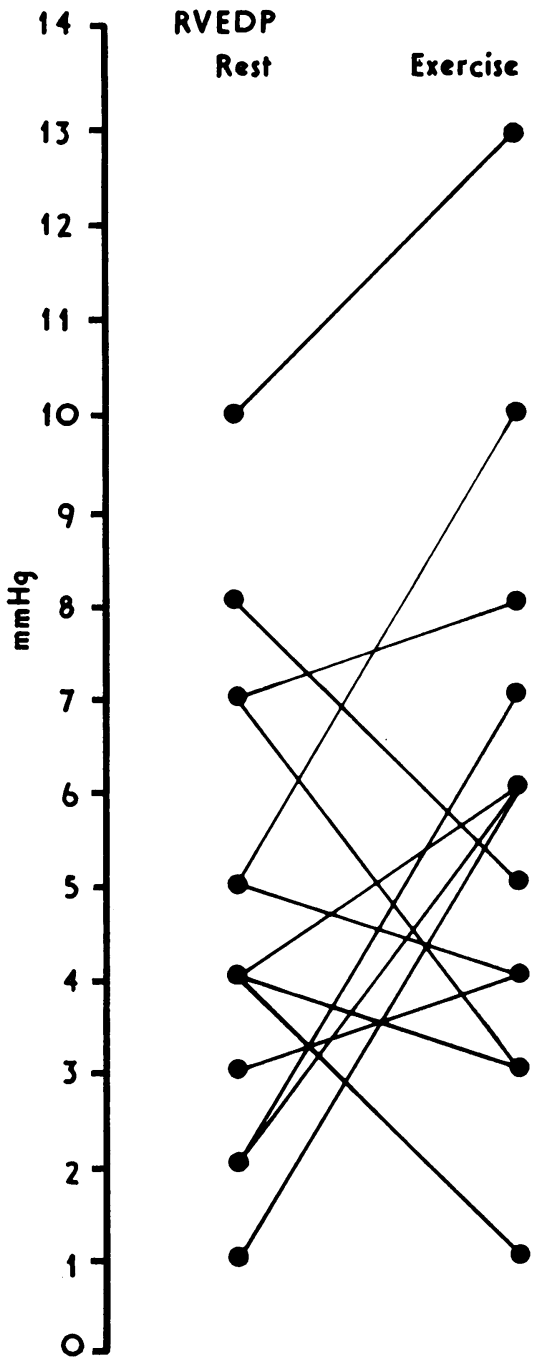

FIG. 2 The right ventricular end-diastolic pressure at rest and during exercise.

Pulmonary diastolic murmurs were present in 5 patients but the right ventricular end-diastolic pressure did not differ significantly from the mean either at rest or during exercise in these patients, indicating that the degree of pulmonary incompetence present was slight.

Cardiac output (Table 3).

The resting cardiac index was $4.01 . / \mathrm{min}$ per $\mathrm{m}^{2}$ $(\mathrm{SD}=0.9)$, and during exercise it increased to $7 \cdot 11 . / \min$ per $\mathrm{m}^{2}(S D=\mathrm{r} \cdot 0)$. The relation between oxygen consumption and cardiac output during exercise was normal in all patients (Fig. 3 ). 
TABLE 3 Postoperative haemodynamic data

\begin{tabular}{|c|c|c|c|c|c|c|c|c|c|}
\hline \multirow[t]{2}{*}{$\begin{array}{l}\text { Case } \\
\text { No. }\end{array}$} & \multirow{2}{*}{$\begin{array}{l}\text { Body surface } \\
\text { area } \\
\left(m^{2}\right)\end{array}$} & \multicolumn{2}{|c|}{ Heart rate/min } & \multicolumn{2}{|c|}{$\begin{array}{l}\text { Cardiac index } \\
\left(\text { l. } / \min \text { per } m^{2}\right)\end{array}$} & \multicolumn{2}{|c|}{$\begin{array}{l}\text { Oxygen uptake index } \\
\left(\mathrm{ml} / \min \text { per } \mathrm{m}^{2}\right)\end{array}$} & \multicolumn{2}{|c|}{$\begin{array}{l}\text { Stroke volume } \\
(\mathrm{ml})\end{array}$} \\
\hline & & Rest & Exercise & Rest & Exercise & Rest & Exercise & Rest & Exercise \\
\hline I & $x \cdot 59$ & 90 & 144 & $4 \cdot 74$ & 8.61 & 149 & 621 & 84 & 95 \\
\hline 2 & $1 \cdot 54$ & 72 & 141 & 5.44 & $9 \cdot 89$ & 183 & 735 & 116 & 108 \\
\hline 3 & 1.60 & 72 & 132 & 474 & 6.41 & 191 & 568 & 105 & 78 \\
\hline 4 & $x \cdot 48$ & 60 & 130 & 3.46 & 6.63 & 106 & 458 & 53 & 75 \\
\hline 5 & $x \cdot 50$ & 70 & 125 & $6 \cdot 02$ & $7 \cdot 11$ & 169 & 784 & 129 & 85 \\
\hline 6 & $I \cdot 37$ & 68 & 114 & 4.07 & 6.99 & 163 & 626 & 82 & 84 \\
\hline 7 & $1 \cdot 83$ & 84 & 108 & $3 \cdot 87$ & 6.50 & 157 & 530 & 84 & IIO \\
\hline 8 & $1 \cdot 66$ & 81 & 144 & 3.35 & $6 \cdot 12$ & 138 & 537 & 69 & 71 \\
\hline 9 & $\mathbf{I} \cdot 70$ & 87 & 123 & $3 \cdot 71$ & $5 \cdot 95$ & 98 & 430 & 72 & 82 \\
\hline 10 & $I \cdot I 6$ & 60 & 100 & $3 \cdot 32$ & 6.73 & 121 & 422 & 60 & 83 \\
\hline I I & $I \cdot 79$ & 69 & II7 & 2.65 & $6 \cdot 37$ & 131 & 616 & 69 & 97 \\
\hline 12 & $I \cdot 25$ & 90 & 126 & 3.65 & $7 \cdot 59$ & I79 & 707 & $5 \mathrm{I}$ & 75 \\
\hline 13 & $\mathbf{I} \cdot 97$ & 84 & 129 & $3 \cdot 67$ & $6 \cdot 57$ & 148 & 492 & 86 & 100 \\
\hline \multirow[t]{3}{*}{14} & $1 \cdot 79$ & 72 & 144 & 3.47 & $7 \cdot 88$ & 126 & 674 & 86 & 98 \\
\hline & Mean $=$ & 75 & 124 & 4.01 & $7 \cdot 10$ & $\mathrm{r} 47$ & 586 & 82 & 89 \\
\hline & $S D=$ & Io & 14 & 0.92 & $I \cdot 04$ & 29 & II4 & 23 & 13 \\
\hline
\end{tabular}

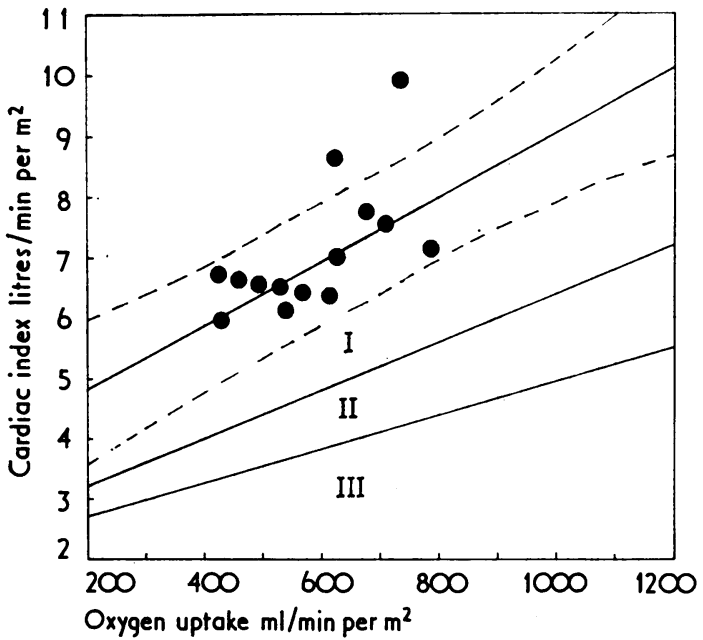

FIG. 3 Relation between cardiac output and oxygen uptake during exercise. The normal regression line and three grades of impairment are also shown (Donald et al., 1955).

Stroke volume (Table 3 and Fig. 4)

The stroke volume rose on exercise in II patients and fell in 3. The mean stroke volume at rest was $82 \mathrm{ml}(\mathrm{SD}=23)$ and on exercise it increased to $89 \mathrm{ml}(\mathrm{SD}=\mathrm{I} 3)$.

\section{Arteriovenous oxygen difference}

The mean arteriovenous oxygen difference at rest was $3.3 \mathrm{vol}$ per cent $(S D=1.5)$ and during exercise it increased to $7 \cdot 3$ vol per cent $(S D=I \cdot 8)$. The response to exercise (Donald et al., I955) was normal in all except one patient.

\section{Discussion}

Patients with mild pulmonary stenosis have normal exercise haemodynamics (Ayres and Lukas, 1960; Lewis et al., 1964; Howitt, 1966; Moller et al., 1972). In our patients with trivial or mild residual pulmonary stenosis after operation the circulatory responses during exercise were also normal.

These results differ from those of Johnson (1962) who found that the response of the cardiac output during exercise was normal in ro patients and abnormal in 7. The abnormal results are probably explained by inadequate relief of the pulmonary stenosis because the mean resting right ventricular systolic pressure for the group was $58 \mathrm{mmHg}$, with a range of 24 to $129 \mathrm{mmHg}$. The age at operation and therefore the duration of the lesion was also greater in this study than in ours.

The results of operation were better in the group studied by Jonsson and Lee (1968); 6 had mild and 3 had moderate residual pulmonary stenosis. Five patients had a normal cardiac output response during exercise, 3 had grade 2 impairment, and I had grade I impairment. This group of patients was also older than ours: their mean age at the time of operation was 35 years.

In normal subjects the response of stroke volume to exercise is variable (Donald et al., 1955); it usually increases or remains the same but it may fall. Moller and his colleagues found that patients with mild pulmonary stenosis increased their stroke volume on exercise; when the stenosis was more severe the stroke volume remained constant (Moller et al., 1972). In our study the stroke volume increased in II patients (mean increase $17 \mathrm{ml}$ ) and fell in 3 (mean fall $26 \mathrm{ml}$ ) (Fig. 4). The stroke index 
Stroke volume $\mathrm{ml}$
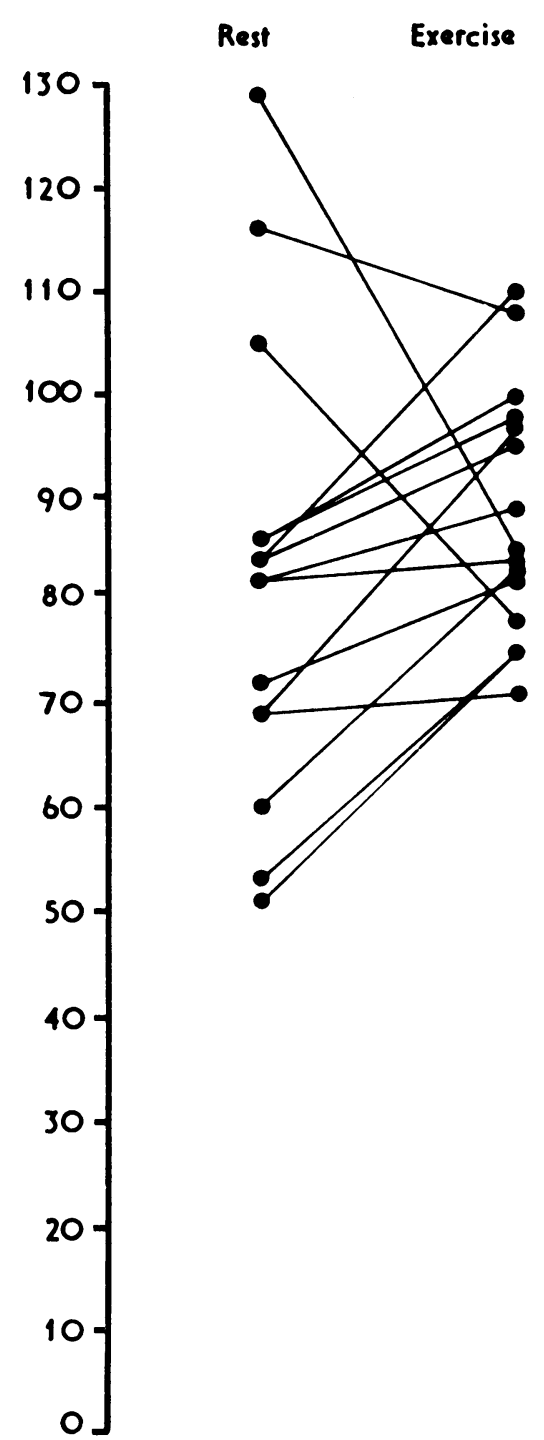

FIG. 4 The stroke volume at rest and during exercise.

increased during exercise in ro patients and this increase was accompanied by a rise in right ventricular end-diastolic pressure in 7 patients (Fig. 5). The right ventricular end-diastolic pressure normally decreases during exercise, and though the increase in our cases never exceeded $5 \mathrm{mmHg}$ it nevertheless probably indicates impairment of right ventricular compliance caused by persisting muscle hypertrophy or myocardial fibrosis. A major fall in stroke index during exercise occurred in 2 patients but it is unlikely that this was caused by impaired

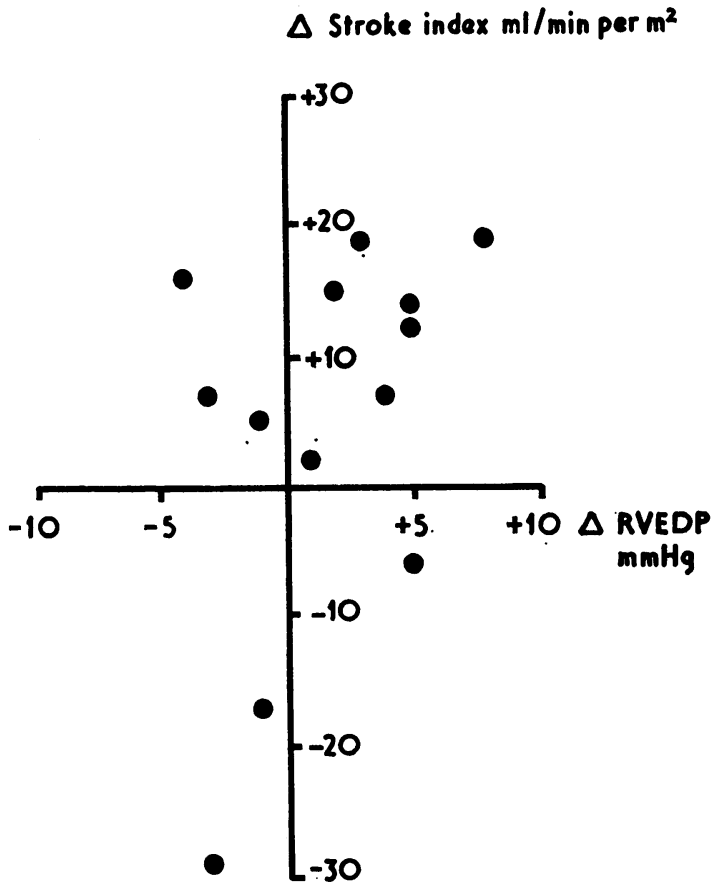

FIG. 5 Changes in stroke index and right ventricular end-diastolic pressure during exercise.

cardiac contractility because the right ventricular end-diastolic pressure also fell in these patients (Fig. 5).

The cardiac output response during exercise was normal in this group of patients whose residual pulmonary stenosis was mild or trivial. It seems likely that the successful surgical relief of the pulmonary stenosis was the most important factor in achieving this result. More detailed studies of myocardial function are necessary to determine the importance of the impairment of right ventricular compliance.

The authors are indebted to Dr. C. G. Parsons and Mr. K. D. Roberts for permission to investigate patients under their care and to Professor J. M. Bishop for making the facilities available.

\section{References}

Allanby, K. D., and Campbell, M. (1949). Congenital pulmonary stenosis with closed ventricular septum. Guy's Hospital Reports, 98, 18.

Ayres, S. M., and Lukas, D. S. (1960). Mild pulmonic stenosis: a clinical and hemodynamic study of eleven cases. Annals of Internal Medicine, 52, 1076.

Donald, K. W., Bishop, J. M., Cumming, G., and Wade, O. L. (1955). The effect of exercise on the cardiac output and circulatory dynamics of normal subjects. Clinical Science, 14, 37. 
Dow, J. W., Levine, H. D., Elkin, M., Haynes, F. W., Hellems, H. K., Whittenberger, J. W., Ferris, B. G., Goodale, W. T., Harvey, W. P., Eppinger, E. C., and Dexter, L. (1950). Studies of congenital heart disease. IV. Uncomplicated pulmonic stenosis. Circulation, I, 267. Goodwin, J. F., and Abdin, Z. H. (1959). The cardiogram of congenital and acquired right ventricular hypertrophy. British Heart fournal, 21, 523.

Howitt, G. (1966). Haemodynamic effects of exercise in pulmonary stenosis. British Heart fournal, 28, 152.

Ikkos, D., Jonsson, B., and Linderholm, H. (I966). Effect of exercise in pulmonary stenosis with intact ventricular septum. British Heart fournal, 28, 316.

Johnson, A. M. (1962). Impaired exercise response and other residua of pulmonary stenosis after valvotomy. British Heart fournal, 24, 375.
Jonsson, B., and Lee, S. J. K. (1968). Haemodynamic effects of exercise in isolated pulmonary stenosis before and after surgery. British Heart fournal, 30, 60 .

Lewis, J. M., Montero, A. C., Kinard, S. A., Dennis, E. W., and Alexander, J. K. (1964). Hemodynamic response to exercise in isolated pulmonic stenosis. Circulation, 29, 854 .

Moller, J. H., Rao, S., and Lucas, R. V. (1972). Exercise hemodynamics of pulmonary valvular stenosis. Circulation, 46, 1018.

Wood, P. (1956). Diseases of the Heart and Circulation, 2nd ed. Eyre and Spottiswoode, London.

Requests for reprints to Dr. P. Finnegan, Department of Medicine, Queen Elizabeth Hospital, Edgbaston, Birmingham BI5 2 TH. 